\title{
Gelatin tannate reduces the proinflammatory effects of lipopolysaccharide in human intestinal epithelial cells
}

This article was published in the following Dove Press journal:

Clinical and Experimental Gastroenterology

7 May 2012

Number of times this article has been viewed

\author{
Giuseppina Frasca' \\ Venera Cardile' \\ Carmelo Puglia ${ }^{2}$ \\ Claudia Bonina ${ }^{2}$ \\ Francesco Bonina ${ }^{2}$ \\ 'Department of Biomedical Sciences \\ (Physiology), ${ }^{2}$ Department of Drug \\ Sciences, University of Catania, \\ Catania, Italy
}

Background: Gelatin tannate is a mixture of tannic acid and gelatin. Tannic acid has astringent properties, due to its capacity to form protein-macromolecular complexes, as well as antibacterial and antioxidant properties. However, little is known about its anti-inflammatory properties.

Purpose: To evaluate the anti-inflammatory activity of gelatin tannate by quantifying the suppression of key molecules produced during inflammatory events in lipopolysaccharide (LPS)-stimulated human intestinal cells.

Methods: Intercellular adhesion molecule-1 (ICAM-1) expression was determined by Western blot analysis; interleukin-8 (IL-8) and tumor necrosis factor- $\alpha$ (TNF- $\alpha$ ) concentrations were measured by enzyme-linked immunosorbent assays in Caco- 2 cells 24 hours after treatment with LPS $(1 \mu \mathrm{g} / \mathrm{mL})$ in presence of different concentrations of gelatin tannate.

Results: ICAM-1 is induced on a wide variety of cells by inflammatory stimuli such as LPS. Our results have shown gelatin tannate as a potent inhibitor of ICAM-1 expression in LPS-stimulated Caco- 2 cells. IL- 8 and TNF- $\alpha$ are important inflammatory mediators, recruiting neutrophils and T-lymphocytes. Together with LPS, adding gelatin tannate at different concentrations induced a dose-dependent inhibition of IL- 8 and TNF- $\alpha$ released by Caco- 2 cells.

Conclusion: These results suggest that gelatin tannate exerts anti-inflammatory effects by inhibiting the specific cytokines and adhesion molecules involved in several inflammatory disorders.

Keywords: Caco-2, ICAM-1, IL-8, TNF- $\alpha$

\section{Introduction}

The gastrointestinal tract not only plays an important role in the absorption, digestion, and exchange of nutrients, but is also the largest organ in the immune system. Under normal conditions, the intestinal immune system is kept in balance, within which pro- and anti-inflammatory cells, along with other molecules, are carefully regulated to promote a normal host mucosal defense capability without destruction of intestinal tissue. ${ }^{1}$ Dysregulation of this balance could lead to pathologic conditions, such as inflammatory bowel conditions characterized by the infiltration of inflammatory cells from the blood circulation, including monocytes, lymphocytes and neutrophils. ${ }^{2,3}$

In response to bacteria, toxins and/or the attachment of antigens, the enterocyte, through signal transduction pathways, stimulates the genes necessary to regulate inflammatory cytokine transcription and translation. ${ }^{4}$ The mucosal immune system is the central catalyst for intestinal inflammation and injury, with cytokines playing a central role in modulating inflammation. ${ }^{5}$ Cytokines may therefore be a logical therapeutic target for inflammatory bowel conditions using specific cytokine inhibitors.
Correspondence: Venera Cardile Department of Biomedical Sciences, University of Catania, V le A Doria 6, 95125 Catania, Italy

Tel +39095 7384040

Fax +390957384217

Email cardile@unict.it which permits unrestricted noncommercial use, provided the original work is properly cited. 
Whilst they are only secondary metabolites of plants, tannins are mostly water-soluble phenolic compounds, and are well known antioxidants sourced from medicinal plants, foods, and edible fruits. Vegetable tannins have attracted a lot of attention in recent years because their multifunctional properties are beneficial to human health. Their diverse biological properties and potential for disease prevention have been demonstrated through various in vitro and in vivo assays. ${ }^{6}$

According to their structure, tannins are categorized as falling into three categories: hydrolyzable tannins, condensed tannins, or complex tannins. ${ }^{7}$ Hydrolyzable tannins are the esters of 3,4,5-trihydroxybenzoic acid (gallic acid). Gallic acid molecules are esterified to a core polyol, and the galloyl groups may be further esterified or oxidatively cross-linked to form more complex structures. Gallotannins, the polygalloyl esters of glucose, are the simplest hydrolyzable tannins. 1,2,3,4,6-penta-O-galloyl- $\beta$-D-glucose (PGG) is a prototypical gallotannin, and the central compound in the biosynthetic pathway of hydrolyzable tannins. ${ }^{8}$ Though PGG itself is thought to stimulate the secretion of tumor necrosis factor- $\alpha$ (TNF- $\alpha$ ) and interleukin- $1 \beta$ (IL-1 $\beta$ ), which are both proinflammatory cytokines, it can also attenuate the stimulating effect of lipopolysaccharide (LPS) when treated together; this effect has been tested in both in vitro and in vivo models. ${ }^{9}$ Additionally, PGG is believed to suppress the expression of adhesion molecules, including intercellular adhesion molecule-1 (ICAM-1) and vascular cell adhesion molecule-1 (VCAM-1), induced by TNF- $\alpha$. The expression of TNF- $\alpha$-induced monocyte chemoattractant protein-1 (MCP-1) has also been shown to be attenuated by PGG. ${ }^{10}$

Tannic acid is a polymer of gallic acid molecules and glucose, and is hydrolyzed into glucose and gallic or ellagic acid units. The natural antioxidant, antimicrobial, and antiviral activity of hydrolyzable tannins such as tannic acid and epigallocatechin gallate have been reported. ${ }^{11-13}$

Tannic acid is present in many different plant species and foods, and is considered a generally recognized safe (GRAS) food substance, as well as an official drug in Europe and North America. ${ }^{11,14}$ As an antioxidant compound, tannic acid was shown to inhibit lipid oxidation and radical-mediated DNA cleavage by scavenging oxygen and oxygen-derived radicals. ${ }^{15,16}$ In addition, numerous studies have suggested that tannic acid has antimicrobial activity against foodborne pathogens such as Escherichia coli and Listeria monocytogenes. ${ }^{17-20}$ Tannic acid has astringent properties due to its ability to form macromolecular complexes with the proteins to which it binds by means of hydrogen links. Some controlled studies have shown tannins to be effective in the treatment of diarrhea, with significantly better results than placebo, shortening the duration of the disorder with no undesirable effects. ${ }^{21,22}$ Tannic acids do have several undesirable gastrointestinal effects: they induce digestive symptoms such as nausea and vomiting whilst inhibiting the absorption of iron and other metals. The use of tannin complexes such as gelatin tannate (TAN), which is hydrolyzed to gelatin and tannic acid upon reaching the intestine, prevents gastric lesions caused by tannic acid.

It has been demonstrated recently that TAN, a mixture of tannic acid and gelatin, exerts an antidiarrhoeal effect. ${ }^{22}$ The efficacy and safety of a similar compound in the treatment of acute diarrhea in pediatric patients were studied by Loeb et al where infants aged 3-21 months with acute diarrhea of bacterial and viral origin randomly received either a tannin-rich carob pod powder or an equivalent placebo for up to 6 days. Participants given the tannate-containing compound showed normalization of defecation, body temperature, and weight, and ceased vomiting much earlier than those who received placebo. $^{21}$

The aim of the present study was to evaluate the potential anti-inflammatory effect of TAN, through an in vitro model to study the immune response of intestinal epithelial cells. The expression of some inflammatory mediators such as ICAM-1, IL-8 and TNF- $\alpha$ was evaluated in human epithelial colorectal adenocarcinoma (Caco-2) cells stimulated with LPS, a major structural component of Gram-negative bacteria, known as one of the most potent inflammatory mediators in intestinal epithelium.

\section{Materials and methods Reagents}

Gelatin tannate $\left(\operatorname{Tasectan}^{\circledR}\right.$; Novintethical Pharma Sagl, Lugano, Switzerland) is composed of tannic acid and gelatin. The gelatin used in the manufacturing of TAN is a type A or acid gelatin with a dissolution $\mathrm{pH}$ of 5.5 and a Bloom gel strength of 40 to $60 \mathrm{~g}$ (viscosity of $27 \mathrm{mPs}$ ).

Gelatin is a pure natural protein, easily digested, with no cholesterol, odor or flavor. Gelatin contains $84 \%-90 \%$ collagen protein, $1 \%-2 \%$ mineral salts, and the rest is water. The protein is composed of 18 amino acids (glycine, 25.5\%; alanine, $8.7 \%$; valine, $2.5 \%$; leucine, $3.2 \%$; isoleucine, $1.4 \%$; cysteine, $0.1 \%$; methionine, $1 \%$; phenylalanine, $2.2 \%$; proline, $18 \%$; hydroxyproline, $14 \%$; serine, $0.4 \%$; threonine, $1.9 \%$; tyrosine, $0.5 \%$, aspartic acid, $6.6 \%$; glutamic acid, $11.4 \%$; arginine, $8.1 \%$, lysine, $4.1 \%$; histidine, $0.8 \%$ ). 


\section{Cell culture and treatments}

Caco- 2 cells were maintained in minimum essential medium (MEM; Sigma-Aldrich, Milan, Italy), supplemented with $10 \%$ fetal calf serum, $100 \mathrm{U} / \mathrm{mL}$ penicillin, and $100 \mu \mathrm{g} / \mathrm{mL}$ streptomycin, incubated at $37^{\circ} \mathrm{C}$ within a humidified $95 \%$ air and $5 \% \mathrm{CO}_{2}$ atmosphere. The medium was changed every 2 to 3 days.

Caco- 2 cells usually reached confluence 3 days after seeding, and differentiated into enterocyte-like cells 18-20 days postconfluence. All experiments were carried out in these fully differentiated cells.

For experiments, 24 hours before they were required, the cells were trypsinized and plated in either 96-well plates (for enzyme-linked immunosorbent assay [ELISA] tests) or $100 \mathrm{~mm}$ Petri dishes (for Western blot). Caco-2 cells were stimulated or not (untreated controls) with LPS at a concentration of $1 \mu \mathrm{g} / \mathrm{mL}$, used to reproduce the mechanisms involved in the pathogenesis of inflammatory processes, in the absence or presence of different concentrations of TAN $(1,10$, and $100 \mu \mathrm{g} / \mathrm{mL})$. After 24-hours' incubation, each sample was tested for ICAM-1 expression, and for IL-8 and TNF- $\alpha$ release.

\section{Western blot analysis}

The expression of ICAM-1 was evaluated by Western blot analysis. Briefly, both the untreated and treated Caco- 2 cells were washed twice with icecold phosphate-buffered saline (PBS) and collected with lysing buffer (10 mM Tris-hydrochloride plus $10 \mathrm{mM}$ potassium chloride, $2 \mathrm{mM}$ magnesium chloride, $0.6 \mathrm{mM}$ phenylmethylsulfonyl fluoride, and $1 \%$ sodium dodecyl sulfate, $\mathrm{pH}$ 7.4). After cooling for 30 minutes at $0^{\circ} \mathrm{C}$, the cells were sonicated. A total protein of $20 \mu \mathrm{g}$, present in the supernatant, was loaded onto each lane and separated by $4 \%$ to $12 \%$ Novex Bis-Tris gel electrophoresis (NuPAGE; Invitrogen, Milan, Italy). Proteins were then transferred into nitrocellulose membranes (Invitrogen) in a wet system. Membranes were blocked with Tris-buffered saline containing $0.1 \%$ Tween-20 (TBST) and 5\% nonfat dry milk at $4{ }^{\circ} \mathrm{C}$ overnight. Mouse monoclonal anti-ICAM-1 (1:200; Santa Cruz Biotechnologies, Santa Cruz, CA), and mouse monoclonal anti- $\alpha$-tubulin antibodies (1:5000; Sigma-Aldrich) were diluted in TBST, and the membranes incubated for 24 hours at room temperature. Antibodies were detected with horseradish peroxidase-conjugated secondary antibody, using the enhanced SuperSignal ${ }^{\circledR}$ West Pico Chemiluminescent Substrate (Pierce Chemical Co, Rockford, IL). Bands were measured densitometrically, and their relative density calculated based on the density of the $\alpha$-tubulin bands in each sample. Values were expressed as arbitrary densitometric units corresponding to signal intensity.

\section{ELISA assay}

IL-8 and TNF- $\alpha$ were measured on cell-free supernatants collected 24 hours after treatment with specific sandwich ELISA (Biotrak, EIA System; Amersham Biosciences, Piscataway, NJ). Cell cultures were carried in triplicate for each condition. All assays were performed as specified by the kit manufacturer. A standard curve was created for each assay using known concentrations of IL- 8 or TNF- $\alpha$ as provided in the kit. Plates were read at $450 \mathrm{~nm}$ using a microplate reader. The amount of cytokines was quantified within each supernatant in duplicate. Results were given as mean (expressed in $\mathrm{pg} / \mathrm{mL}$ ) and standard error of the mean (SEM).

\section{MTT assay}

The cytotoxic effect of the experimental substance was evaluated using a cell viability test based on the cleavage of 3-(4,5-dimethylthiazol-2-yl)-2,5-diphenyltetrazolium bromide (MTT) by mitochondrial dehydrogenases from metabolically active cells. Cellular growth was determined using the MTT assay on 96-well microplates. The optical density of each well sample was measured with a microplate spectrophotometer reader at $550 \mathrm{~nm}$.

\section{Statistical analysis}

All statistical analyses were performed with the statistical software package SYSTAT (v 9.0; Systat Inc, Evanston, IL). Each result was calculated as the mean value and SEM. Statistical significances between paired and unpaired values were performed using the Student's $t$-test. $P<0.05$ were considered statistically significant.

\section{Results}

ICAM-1 expression was analyzed at 24 hours in Caco- 2 cells treated with LPS $(1 \mu \mathrm{g} / \mathrm{mL})$. Western blot analysis revealed no constitutive expression of ICAM-1 protein in Caco-2 cells, whereas incubation of cultures with LPS for 24 hours induced a strong expression of ICAM-1. Addition of TAN at different concentrations together with LPS induced a dose-dependent inhibition of ICAM-1 expression (Figure 1). At the highest dose, TAN blocked ICAM-1 expression by $69 \%$. TAN did not induce ICAM-1 expression as noted by the lack of bands in the lane corresponding to the treatment of cells with the test product.

The expression of both TNF- $\alpha$ and IL-8 was analyzed in Caco-2 cells treated with LPS $(1 \mu \mathrm{g} / \mathrm{mL})$ by ELISA 

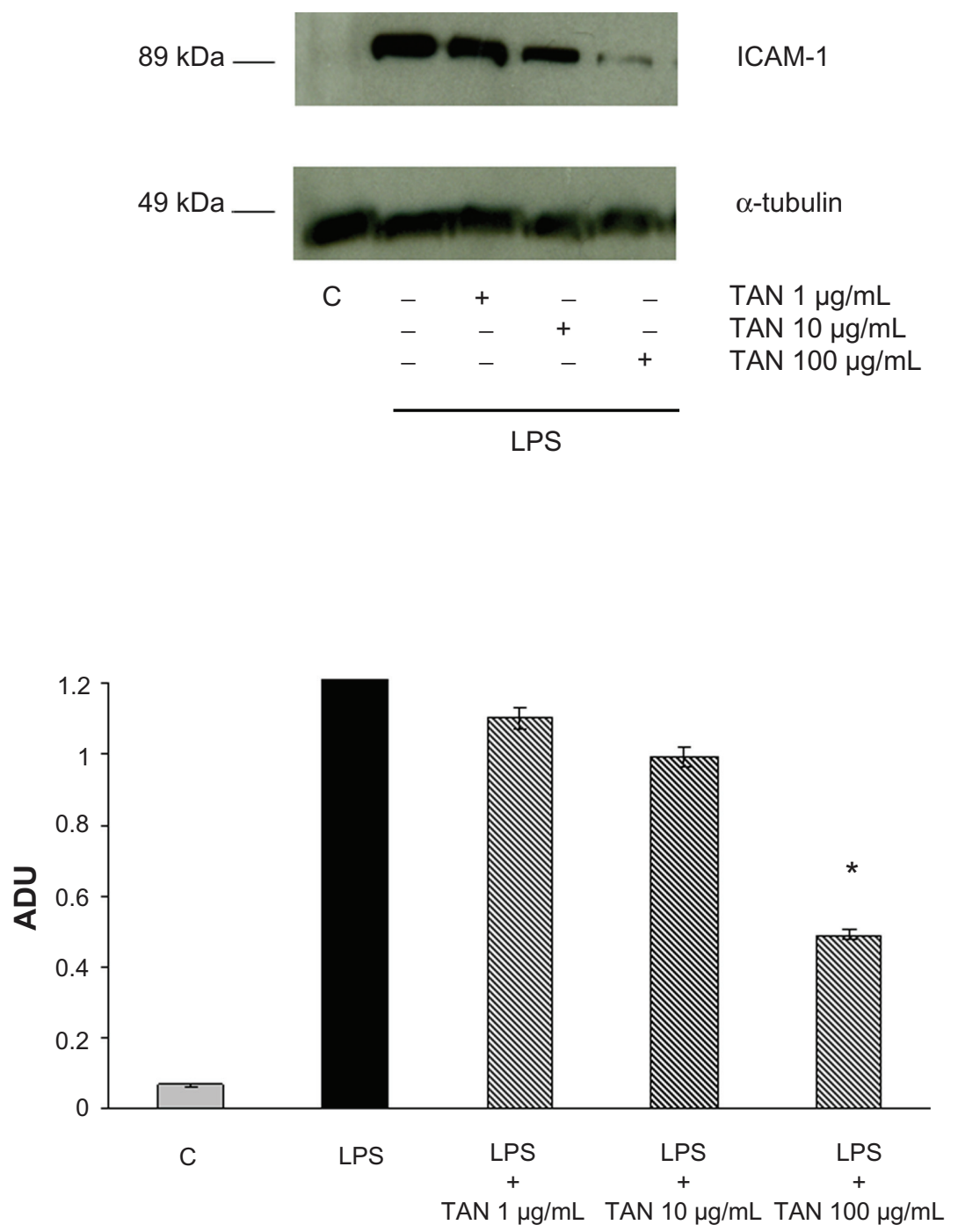

Figure I Effects of TAN on ICAM-I expression induced by LPS in human Caco-2 cells determined by Western blot analysis.

Notes: Data shows the relative expression (mean + SEM) of ICAM-I calculated as ADU collected from three independent experiments. *P $<0.05$ compared with TANinduced ICAM-I.

Abbreviations: ADU, arbitrary densitometric units; ICAM-I, intracellular adhesion molecule-I; LPS, lipopolysaccharide; SEM, standard error of mean; TAN, gelatin tannate.

assay at 24 hours. Only a negligible amount of TNF- $\alpha$ was produced by unstimulated Caco- 2 cells, but TNF- $\alpha$ was markedly induced by LPS (Figure 2). TAN markedly inhibited LPS-induced release of TNF- $\alpha$ : at a lower concentration $(1 \mu \mathrm{g} / \mathrm{mL})$ there was a very significant inhibition (-35\%), that further increased at higher (10 and $100 \mu \mathrm{g} / \mathrm{mL})$ concentrations of TAN ( $-43 \%$ and $-63 \%$ respectively) (Figure 2). The effects of TAN on the release of IL-8 were also investigated. Very low amounts of IL-8 were produced by unstimulated cells. By contrast, LPS potently induced IL-8, which was markedly decreased by TAN in a dose-dependent manner (Figure 3). Inhibition of LPS-induced inflammatory mediator expression in Caco- 2 cells by TAN was not due to TAN cytotoxicity, as assessed by MTT assay (Figure 4).

\section{Discussion}

Our results suggest that TAN has a remarkable antiinflammatory potential due to its strong ability to inhibit inflammatory biomarkers, such as LPS-induced ICAM-1, IL-8, and TNF- $\alpha$ in Caco- 2 cells.

The intestinal epithelium is able to secrete cytokines and other mediators of inflammation, to respond to growth factors and cytokines released by lymphoid cells, and to express integrins and HLA class II molecules, which permits direct cell-to-cell communication with inflammatory and immune cells. ${ }^{22}$ Evidence indicates that a dysregulation of intestinal mucosal immunity, as often seen in inflammatory bowel conditions, causes an overproduction of inflammatory cytokines and the trafficking of catalyst leukocytes into the bowel, thus leading to an uncontrolled intestinal inflammation. ${ }^{24}$ 


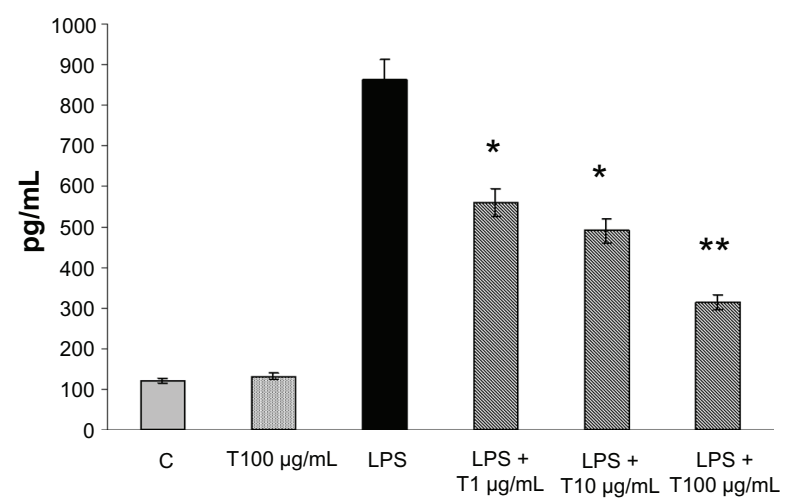

Figure 2 TNF- $\alpha$ production (mean + SEM) measured in the culture media by enzyme-linked immunosorbent assay from Caco-2 cells 24 hours after the addition of TAN together with LPS.

Notes: Values are expressed as $\mathrm{pg} / \mathrm{mL}$. $* P<0.05$ and $* * P<0.01$; significantly different from LPS-treated samples.

Abbreviations: LPS, lipopolysaccharide; SEM, standard error of mean; TAN, gelatin tannate; TNF- $\alpha$, tumor necrosis factor- $\alpha$.

Proinflammatory cytokines/chemokines produced in the intestine play an important role in the pathogenesis of complications of critical illness. One of these, IL-8, has been shown to be a particularly potent chemoattractant for leukocytes and subsequent inflammation. ${ }^{25}$ IL-8 initiates the acute inflammatory cascade, and is also an early marker of the inflammatory process; its expression must be controlled to prevent both excessive tissue injury, and damage to local and distal organs. ${ }^{26}$

ICAM-1 is a cytokine-inducible glycoprotein belonging to the immunoglobulin supergene family. ICAM-1 is constitutively expressed at low levels on a limited number of cell types, including endothelial cells, ${ }^{28,29}$ but its expression is markedly upregulated on a wide variety of cells by inflammatory cytokines such as IL-1 $\beta$, TNF- $\alpha$, and interferon- $\gamma($ IFN- $\gamma){ }^{30,31}$

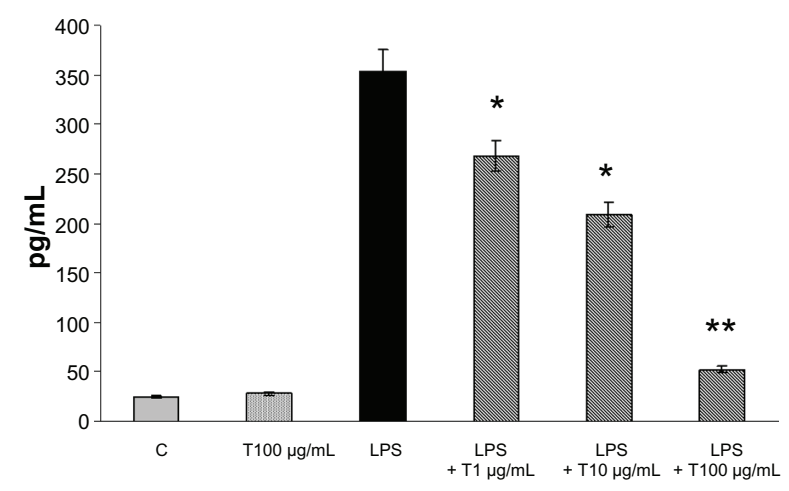

Figure 3 IL-8 production (mean + SEM) measured in the culture media by enzymelinked immunosorbent assay from Caco- 2 cells 24 hours after the addition of TAN together with LPS.

Notes: Values are expressed as $\mathrm{pg} / \mathrm{mL}$. $* P<0.05$ and $* * P<0.01$; significantly different from LPS-treated samples.

Abbreviations: IL-8, interleukin-8; LPS, lipopolysaccharide; SEM, standard error of mean; TAN, gelatin tannate.

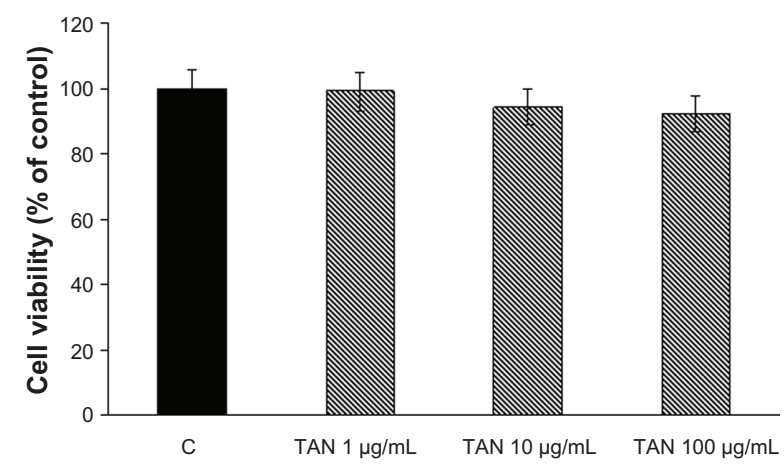

Figure 4 Cell viability evaluated by the MTT proliferation assay on Caco- 2 cells 24 hours after the addition of TAN at different concentrations.

Note: The values are the mean \pm SEM of three experiments performed in triplicate. Abbreviations: MTT, tetrazolium-based colorimetric assay; SEM, standard error of mean; TAN, gelatin tannate.

ICAM-1 participates in leucocyte adhesion to activated endothelial cells, $\mathrm{T}$ cell/antigen-presenting cells, $\mathrm{T}$ cellto-T cell, and $\mathrm{T}$ cell/B cell interactions. ${ }^{32}$ Several epithelial cell types express ICAM-1, including human colonic adenocarcinoma cell lines and colonic cancer cells in vivo. ${ }^{33}$ By downregulating the expression of these molecules on the endothelium, their interaction with immune cells will be reduced and inflammatory activity diminished. This mechanism of action may be of importance to induce remission in inflammatory bowel conditions.

TAN is a mixture of tannic acid and gelatin with antidiarrheal effects. TAN also has attributed antibacterial and antioxidant properties, representing an advantage in the empiric use of conventional antibiotics that can contribute to the development of resistance and dysbacteriosis. ${ }^{33,34}$ Additionally, unlike other antidiarrheal agents such as loperamide ${ }^{35}$ it has no effect upon the central nervous system, and no other undesirable effects such as reactive constipation. More recently, a study reported no TAN-related undesirable effects either during or after treatment of acute diarrhea in children with a mean age of 2.5 years (standard deviation, 2.4; median, 1.7 years); the product was also well tolerated. ${ }^{22}$

This study demonstrates that the mixture of tannic acid and gelatin acts as a potent inhibitor of ICAM-1 (Figure 1)<smiles>CC(=O)c1cc(O)c(O)c(OC(=O)c2cc(O)c(O)c(O)c2)c1</smiles>

Scheme I Tannic acid.

Note: Molecular formula: $\mathrm{HCl} 4 \mathrm{H} 9$ O9; Molecular weight: 321.22. 
gene expression whilst also suppressing the production of IL-8 (Figure 2) and TNF- $\alpha$ (Figure 3 ) in human enterocytes stimulated with LPS. Previous research has shown that these are key mediators in the pathogenesis of inflammatory bowel conditions, and that the reduction of these mediators has been associated with the amelioration of inflammatory conditions. ${ }^{36,37}$ The present in vitro study suggests that TAN contributes to decrease the expression and production of such inflammatory mediators in Caco-2 cells. It found, in fact, that TAN inhibits ICAM-1 expression in LPS-stimulated cells, and that it probably acts at the transcriptional level, as evidenced by dose-dependent reductions in its levels of expression.

TAN was also found to decrease the release of IL- 8 and TNF- $\alpha$. IL- 8 is known to be an important cytokine for controlling leukocyte trafficking, and the recruitment of both neutrophils and T lymphocytes. TNF- $\alpha$ is a cytokine involved in systemic inflammation, and belongs to a group of cytokines that stimulate the acute phase reaction. Dysregulation of TNF- $\alpha$ production has been implicated in a variety of human diseases, including inflammatory bowel disease (IBD). ${ }^{38}$ The treatment of IBD has advanced in parallel to the improvement of the knowledge of its physiopathology, leading to the development of biological therapies. An example of this kind of treatment is the use of substances that antagonize TNF- $\alpha$, such as monoclonal antibodies; several studies have demonstrated that inhibition of TNF- $\alpha$ is useful in the treatment of IBD. ${ }^{39,40}$

It has been reported recently that a member of the tannin family, known as PGG, is an effective immunoregulator of the LPS-mediated TNF- $\alpha$ response in both human peripheral blood mononucleocytes, and in live rats. PGG was shown to possess anti-inflammatory properties, even if PGG itself stimulated the production of TNF- $\alpha$ and IL- $1 \beta .{ }^{9}$ Here, we demonstrate that TAN exerts its beneficial properties without inducing the production of inflammatory mediators.

\section{Conclusion}

In summary, the present results suggest that TAN could be used not only for its antidiarrheal effect, due to astringent properties, but also for the treatment of intestinal disorders such as inflammatory bowel conditions where inflammatory mediators may play a key role. Our data indicates that TAN may be effective, with minimal or no toxicity, in the treatment of intestinal inflammatory conditions.

\section{Acknowledgments}

The present study was funded by an unrestricted grant from Novintethical Pharma Sagl. The sponsor of the study played no role in the study design, data collection, data analysis, interpretation, writing of the manuscript, or the decision to submit the manuscript for publication. The authors wish to thank Rita Moreira da Silva for editing the manuscript.

\section{Disclosure}

The authors declare no conflict of interest in this work.

\section{References}

1. MacDermott RP. Alterations of the mucosal immune system in inflammatory bowel disease. J Gastroenterol. 1996;31(6):907-916.

2. Huang Y, Li N, Liboni K, Neu J. Glutamine decreases lipopolysaccharide-induced IL-production in Caco-2 cells through a non-NF-kappaB p50 mechanism. Cytokine. 2003;22(3-4):77-83.

3. Eckmann L, Jung HC, Schürer-Maly C, PanjaA, Morzycka-WroblewskaE, Kagnoff MF. Differential cytokine expression by human intestinal epithelial cell lines: regulated expression of interleukin 8. Gastroenterology. 1993;105(6):1689-1697.

4. Walker WA. Role of nutrients and bacterial colonization in the development of intestinal host defense. J Pediatr Gastroenterol Nutr. 2000; 30(Suppl 2):S2-S7.

5. Ardizzone S, Bianchi Porro G. Biologic therapy for inflammatory bowel disease. Drugs. 2005;65(16):2253-2286.

6. Yoshida T, Amakura Y, Yoshimura M. Structural features and biological properties of ellagitannins in some plant families of the order myrtales. Int J Mol Sci. 2010;11(1):79-106.

7. Yoshida T, Hatano T, Ito H. High molecular weight plant polyphenols (tannins): Prospective functions. Recent Adv Phytochemistry. 2005;39:163-190

8. Zhang J, Li L, Kim SH, Hagerman AE, Lü J. Anti-cancer, anti-diabetic and other pharmacologic and biological activities of penta-galloylglucose. Pharm Res. 2009;26(9):2066-2080.

9. Feldman KS, Sahasrabudhe K, Lawlor MD, Wilson SL, Lang CH, Scheuchenzuber WJ. In vitro and in vivo inhibition of LPSstimulated tumor necrosis factor-alpha secretion by the gallotannin beta-D-pentagalloylglucose. Bioorg Med Chem Lett. 2001;11(14): 1813-1815.

10. Kang DG, Moon MK, Choi DH, Lee JK, Kwon TO, Lee HS. Vasodilatory and anti-inflammatory effects of the 1,2,3,4,6-penta-Ogalloyl-beta-D-glucose (PGG) via a nitric oxide-cGMP pathway. Eur J Pharmacol. 2005;524(1-3):111-119.

11. Akiyama H, Fujii K, Yamasaki O, Oono T, Iwatsuki K. Antibacterial action of several tannins against Staphylococcus aureus. J Antimicrob Chemother. 2001;48(4):487-491.

12. Chung KT, Wong TY, Wei CI, Huang YW, Lin Y. Tannins and human health: a review. Crit Rev Food Sci Nutr. 1998;38(6):421-464.

13. Kaur S, Grover IS, Singh M, Kaur S. Antimutagenicity of hydrolyzable tannins from Terminalia chebula in Salmonella typhimurium. Mutat Res. 1998;419(1-3):169-179.

14. Shi TS. Use of combined traditional Chinese and western medicine in the management of burns. Panminerva Med. 1983;25(3):197-202.

15. Khan NS, Ahmad A, Hadi SM. Anti-oxidant, pro-oxidant properties of tannic acid and its binding to DNA. Chem Biol Interact. 2000;125(3):177-189.

16. Sanchez-Moreno C, Larrauri AJ, Saura-Calixto F. Free radical scavenging capacity and inhibition of lipid oxidation of wines, grape juices and related polyphenolic constituents - history, production and role in disease prevention. Food Res Int. 1999;32(6):407-412.

17. Chung KT, Stevens SE Jr, Lin WF, Wei CI. Growth inhibition of selected foodborne bacteria by tannic acid, propyl gallate and related compounds. Lett Appl Microbiol. 1993;17(1):29-32.

18. Chung KT, Lu Z, Chou MW. Mechanism of inhibition of tannic acid and related compounds on the growth of intestinal bacteria. Food Chem Toxicol. 1998;36(12):1053-1060. 
19. Scalbert A. Antimicrobial properties of tannins. Phytochemistry. 1991;30(12):3875-3883.

20. Taguri T, Tanaka T, Kouno I. Antimicrobial activity of 10 different plant polyphenols against bacteria causing food-borne disease. Biol Pharm Bull. 2004;27(12):1965-1969.

21. Loeb H, Vandenplas Y, Würsch P, Guesry P. Tannin-rich carob pod for the treatment of acute-onset diarrhea. J Pediatr Gastroenterol Nutr. 1989;8(4):480-485.

22. Esteban Carretero J, Durbán Reguera F, López-Argüeta Alvarez S, López Montes J. A comparative analysis of response to ORS (oral rehydration solution) vs ORS + gelatin tannate in two cohorts of pediatric patients with acute diarrhea. Rev Esp Enferm Dig. 2009;101(1):41-48.

23. Brandtzaeg P. Molecular and cellular aspects of the secretory immunoglobulin system. APMIS. 1995;103(1):1-19.

24. Gibson P, Anderson R, Mariadason J, Wilson AJ. Protective role of the epithelium of the small intestine and colon. Inflamm Bowel Dis. 1996;2(4):279-302.

25. Baggiolini M. Chemokines in pathology and medicine. J Intern Med. 2001;250(2):91-104

26. De Dooy JJ, Mahieu LM, Van Bever HP. The role of inflammation in the development of chronic lung disease in neonates. Eur J Pediatr. 2001;160(8):457-463.

27. Vignola AM, Chanez P, Campbell AM, et al. Quantification and localization of HLADR and intercellular adhesion molecule-1 (ICAM-1) molecules on bronchial epithelial cells of asthmatics using confocal microscopy. Clin Exp Immunol. 1994;96(1):104-109.

28. Elgavish A. Effects of Escherichia coli and E. coli lipopolysaccharides on the function of human ureteral epithelial cells cultured in serum-free medium. Infect Immun. 1993;61(8):3304-3312.

29. Chan RD, Greenstein SM, Sablay L, et al. Analysis of adhesion molecule expression by tubular epithelial cells using urine immunocytology. Acta Cytol. 1995;39(3):435-442.
30. Albelda SM, Smith CW, Ward PA. Adhesion molecules and inflammatory injury. FASEB J. 1994;8(8):504-512.

31. Simmons DL. The role of ICAM expression in immunity and disease. Cancer Surv. 1995;24:141-155.

32. Kelly CP, O'Keane JC, Orellana J, et al. Human colon cancer cells express ICAM-1 in vivo and support LFA-1 dependent lymphocyte adhesion in vitro. Am J Physiol. 1992;263(6 Pt 1):G864-G867.

33. Huang GT, Eckmann L, Savidge TC, Kagnoff MF. Infection of human intestinal epithelial cells with invasive bacteria upregulates apical intercellular adhesion molecule-1 (ICAM)-1) expression and neutrophil adhesion. J Clin Invest. 1996;98(2):572-583.

34. Mensa L, Marco F, Vila J, Gascón J, Ruiz J. Quinolone resistance among Shigella spp. isolated from travellers returning from India. J Clin Microbiol Infect. 2008;14(3):279-281.

35. Li ST, Grossman DC, Cummings P. Loperamide therapy for acute diarrhea in children: systematic review and meta-analysis. PLoS Med. 2007;4(3): 98 .

36. Baumgart DC, Sandborn WJ. Inflammatory bowel disease: clinical aspects and established and evolving therapies. Lancet. 2007;369(9573): 1641-1657.

37. Ghosh S, Panaccione R. Anti-adhesion molecule therapy for inflammatory bowel disease. Therap Adv Gastroenterol. 2010;3(4): 239-358.

38. Brynskov J, Foegh P, Pedersen G, et al. Tumour necrosis factor alpha converting enzyme (TACE) activity in the colonic mucosa of patients with inflammatory bowel disease. Gut. 2002;51(1):37-43.

39. Perrier C, Rutgeerts P. Cytokine blockade in inflammatory bowel diseases. Immunotherapy. 2011;3(11):1341-1352.

40. Magro F, Portela F. Management of inflammatory bowel disease with infliximab and other anti-tumor necrosis factor alpha therapies. BioDrugs. 2010;24 Suppl 1:3-14.
Clinical and Experimental Gastroenterology

\section{Publish your work in this journal}

Clinical and Experimental Gastroenterology is an international, peerreviewed, open access journal, publishing all aspects of gastroenterology in the clinic and laboratory, including: Pathology, pathophysiology of gastrointestinal disease; Investigation and treatment of gastointes tinal disease; Pharmacology of drugs used in the alimentary tract;

\section{Dovepress}

Immunology/genetics/genomics related to gastrointestinal disease. This journal is indexed on CAS. The manuscript management system is completely online and includes a very quick and fair peer-review system. Visit http://www.dovepress.com/testimonials.php to read real quotes from published authors. 